\title{
A review of beam pumping energy-saving technologies
}

\author{
Zi-Ming Feng ${ }^{1} \cdot$ Jing-Jing Tan ${ }^{1} \cdot$ Qi Li $^{2} \cdot$ Xin Fang ${ }^{1}$
}

Received: 11 January 2017/Accepted: 13 August 2017/Published online: 29 August 2017

(c) The Author(s) 2017. This article is an open access publication

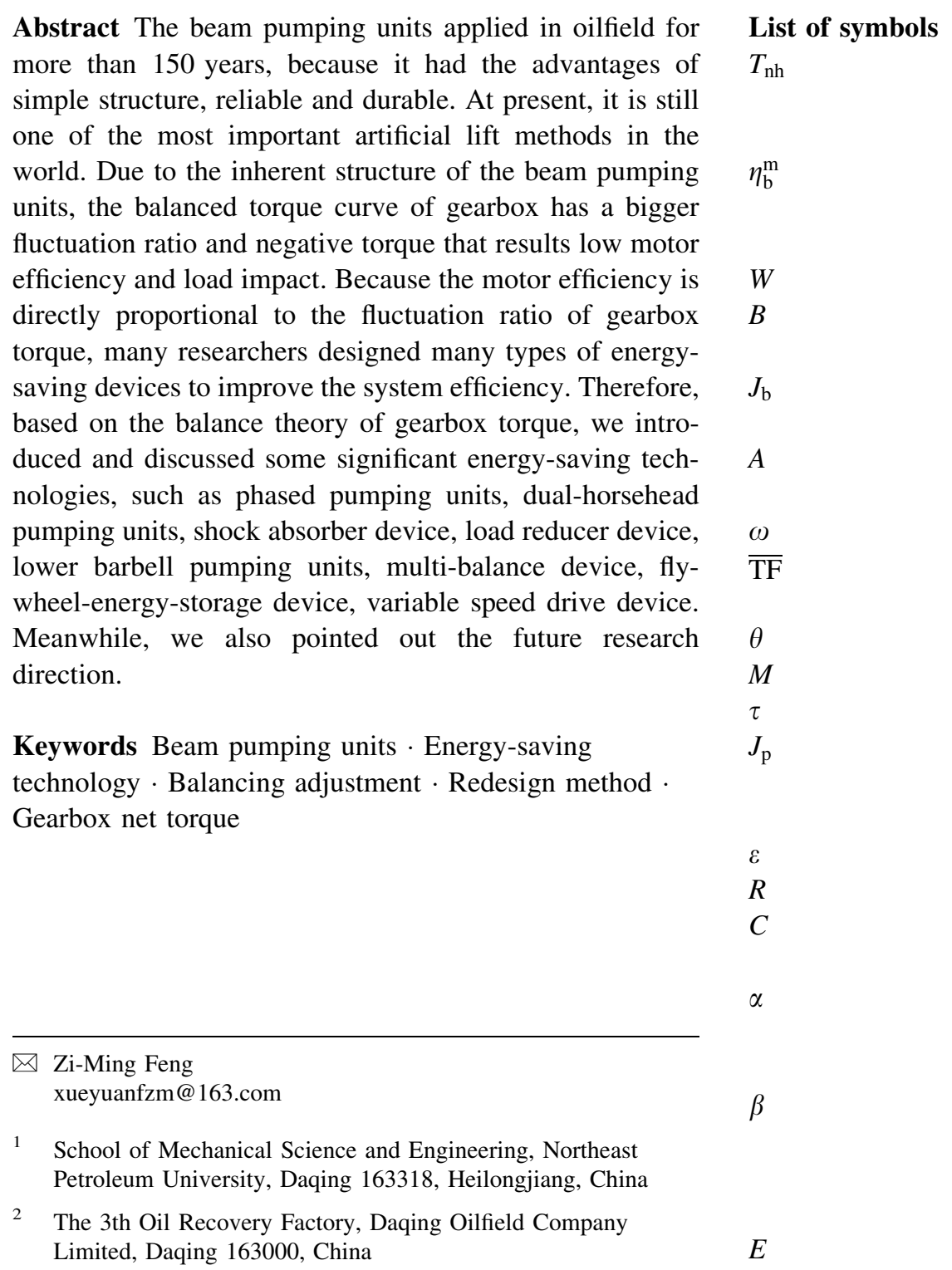

The net torque on output shaft of reduction gearbox, $\mathrm{kN} \mathrm{m}$;

Transmission efficiency of four-bar linkage, dimensionless;

Suspension load, kg;

Unbalance weight of walking beam, $\mathrm{kg}$;

Rotational inertia of walking beam, $\mathrm{kg} \mathrm{m}^{2}$;

The fore arm of beam pumping units, $\mathrm{m}$;

Crank velocity, $\mathrm{rad} / \mathrm{t}$;

Torque factor, dimensionless;

Crank angle, ${ }^{\circ}$;

Balance torque, $\mathrm{kN} \mathrm{m}$;

Crank polarization angle, ${ }^{\circ}$;

Rotational inertia of all the revolving members acting on crankshaft, $\mathrm{kg} \mathrm{m}^{2}$;

Crank acceleration, $\mathrm{rad} / \mathrm{t}^{2}$;

Radius of crank, m;

Rear arm length of walking beam, m;

The intersection angle between based-rod and $Y$ axis, ${ }^{\circ}$;

The intersection angle between based-rod and connection line-between the two fulcrums, ${ }^{\circ}$;

The energy consumption;

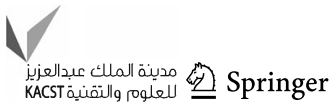




$\begin{array}{ll}T & \text { The input torque; } \\ v & \text { The rotational speed of the } \\ & \text { prime motor; } \\ & \text { The running time of the } \\ & \text { prime motor; } \\ & \text { The transmission efficiency } \\ \eta_{\text {motor }}, \eta_{\text {belt }}, \eta_{\text {gearbox }}, \eta_{\text {fourbar }} & \text { of prime motor, belt, } \\ & \text { gearbox, four-bar linkage, } \\ & \text { respectively; } \\ & \text { The output power of prime } \\ & \text { motor, kW }\end{array}$

\section{Introduction}

The beam pumping units had been used for more than 150 years (Beckwith 2014), because it had the advantages including simple structure, reliable and durable, convenient maintenance and so on. The number of the beam pumping units was accounting for about $21 \%$ of the total wells (Takacs 2015). In the USA, there were 350,000 sucker-rod pumping installations in 2007 (Takacs 2015). In the China, there were nearly 160,000 wells using sucker-rod pumping in 2014 , and the oil pumping units were about $80 \%$ in the oil field. At the same time, the electricity consumption of the artificially lifted well was about $33.38 \%$ of the total power consumption (Zhou 2011).

Due to the inherent characteristics of the four-bar linkage of the beam pumping units, although the torque balance reaches the industry standards, it still has many disadvantages, such as poor balance effect, bigger fluctuation of gearbox torque, existence of negative torque, lower work efficiency, bigger consumption of energy, phenomenon of "a big horse pulls a small carriage". Most of the system efficiency of the beam pumping units is less than $30 \%$ (Zhou 2011); this means that will waste vast energy.

The beam pumping units can be simplified to the fourbar linkage; the rotary motion of the motor is converted into the reciprocating motion of the rod pump with low transmission efficiency. The torque of gearbox is cyclical and like a sinusoidal curve. Some researchers (Zhang and Li 2009; Zou et al. 2005) attempt to make the gearbox static torque relatively flat as far as possible by taking a variety of energy-saving technology, to decrease the peak torque and the root mean square torque, and eliminate the negative torque in order to decrease energy consumption.

To improve the system efficiency and working performance of beam pumping units, many production engineers devoted to research many energy-saving technologies for the beam pumping units based on the gearbox torque curve, and some technologies had achieved very good effects.
This paper will introduce some technologies such as phased pumping units, dual-horsehead pumping units, shock absorber device, load reducer device, lower barbell pumping units, multi-balance device, flywheel-energystorage device, and variable speed drive device. Meanwhile, we also discuss their merits, demerits and the future research direction.

\section{Principle of work of beam pumping units}

The working principle of the beam pumping units is as follow: firstly, the motor converts the electrical energy into the rotational motion. Secondly, after twice reduction by the gearbox and the four-bar linkage, the rotary motion transforms into a linear reciprocating motion. At last, by the horse head, the beam hanger and the polished rod, the sucker rod drives the deep oil well pump. The core component of the beam pumping units is the four-bar linkage that is composed of the crank, the link bar, the rear arm, the connection line between the gearbox shaft and the shaft of the support. The four-bar linkage has the function that transforms the rotary motion of the gearbox into the reciprocating motion required to operate the downhole pump. The geometric parameters of the four-bar linkage have extremely important impact to the contour size and the working performance of the beam pumping units.

For the beam pumping units, reduction of the polished rod load or the gearbox net torque is an effective method to improve its system performance, because the amplitude value and the fluctuation of the gearbox net torque reflect the running condition of this oil wells system. The oilfield engineers had redesigned the beam pumping units by many methods in order to decrease the polish load and the energy.

In this paper, we selected the CYJ10-3-37HB (Min et al. 2006) as the comparison criteria to analysis the effect of these energy-saving technologies for the beam pumping units. Its structure parameters and working parameters are shown in Tables 1 and 2 (Min et al. 2006), respectively.

The gearbox output axial-torque is composed of suspension load torque, balance torque, walking beam inertial torque and crank inertial torque. When the working velocity changes, the computing formula generally cannot ignore the influent of walking beam inertia and crank inertia. Equation (1) expresses the net torque on output shaft of reduction gearbox including walking beam inertia and crank inertia (Wu et al. 1994).

Many energy-saving technologies for the beam pumping units were used by changing their construction, sizes or adding other components to decrease the fluctuation rate and the peak torque of the net output torque of gearbox for the effect of energy-saving, load reduction and running 
Table 1 Structure parameters and working parameters of CYJ10-337HB

\begin{tabular}{ll}
\hline Structure parameters $(\mathrm{mm})$ & Value \\
\hline Length of fore arm & 3000 \\
Length of aft arm & 2400 \\
Length of linkage rod & 3350 \\
Horizontal throw & 2300 \\
Crank radius & 1150 \\
\hline
\end{tabular}

Table 2 Oil well condition and working parameters

\begin{tabular}{ll}
\hline Working parameters & Value \\
\hline Stroke times (1/min) & $9,6,3$ \\
Stroke (m) & $2,2.5,3$ \\
Depth of plunger (m) & 1000 \\
Working fluid level (m) & 600 \\
Pump diameter (mm) & 57 \\
Rod diameter (mm) & 22 \\
Tube diameter (mm) & 76 \\
Water cut $(\%)$ & 90 \\
\hline
\end{tabular}

with safety. So, relying on the components of the gearbox output torque as shown in Eq. (1), the application status of the energy-saving methods and technologies was discussed about in detail, respectively.

$$
\begin{aligned}
T_{\mathrm{nh}}= & \eta_{\mathrm{b}}^{\mathrm{m}}\left[W-B+\frac{J_{\mathrm{b}}}{A}\left(\frac{\omega^{2}}{A} \cdot \frac{\mathrm{d} \overline{\mathrm{TF}}}{\mathrm{d} \theta}+\frac{\overline{\mathrm{TF}}}{A} \cdot \omega \frac{\mathrm{d} \omega}{\mathrm{d} \theta}\right)\right] \overline{\mathrm{TF}} \\
& -M \sin (\theta+\tau)+J_{\mathrm{p}} \varepsilon
\end{aligned}
$$

The energy consumption equation of the prime motor was as follows:

$E=\int_{0}^{t} T v \mathrm{~d} t$

Because the rotational speed of the prime is constant, the energy consumption is directly proportional to the input torque. Decreasing the torque fluctuation ratio of the gearbox will decrease the energy consumption of the prime motor and improving the motor efficiency. In this paper, we collected and talked about some energy-saving devices in the existence documents based on Eq. (1). Because of decreasing any part's value in Eq. (1), such as $W, B$ and $M$, we will decrease the energy consumption $E$. Therefore, based on Eq. (1), we discussed the every terms' impact on the pumping system and at last pointed out the research direction for the energy-saving technology of beam pumping units.

\section{Review of energy-saving technology based on decreasing torque}

\section{Transmission efficiency of ground equipment, $\eta_{\mathbf{b}}^{\mathbf{m}}$}

Generally, the efficiency of ground equipment was divided into two parts: one was the efficiency of prime motor, the other was the comprehensive transmission efficiency of the remaining mechanical movement including belt, gearbox, four-bar linkage, which is $\eta_{\mathrm{b}}^{\mathrm{m}}$.

A transmission efficiency testing for pumping system was conducted by Brown that obtained the correlation between the transmission efficiency and the beam pumping units using rolling bearings and sliding bearings. Two transmission ratio curves are shown in Fig. 1 (Brown 1980) by Brown. Obviously, the rolling bearings had higher transmission efficiency than the sliding bearings. Figure 1 also indicates when the load rate of beam pumping units was less than 5\%, the transmission efficiency was less than $40 \%$. We could consider that the beam pumping units had a relatively high transmission efficiency values in the scope of $5-100 \%$ load rate. Therefore, the transmission efficiency of beam pumping units was often calculated by a constant value $90 \%$ in the general engineering application.

In 2013, Zhang and Feng (2015) conducted a serials testing for the transmission efficiency of prime motor, belt, gearbox and four-bar linkage. He achieved the correlation functions for their transmission efficiency as shown in Table 3. The prime motor was a $22 \mathrm{~kW}$ three-phase asynchronous motor. The beam pumping unit was CYJ103-37HB. The tests were carried out in the simulation oil well with $1000 \mathrm{~m}$ depth of pump in Daqing oilfield.

Some engineers simplified the calculation of the transmission efficiency for pumping units. They considered that the transmission efficiency of the triangular belt, the gearbox and the four-bar linkage were 3, 4 and 3\%, respectively (Brown 1980). Certainly, they must regularly inspect and maintain the belt and the bearings to ensure the adequate lubrication for a high transmission efficiency.

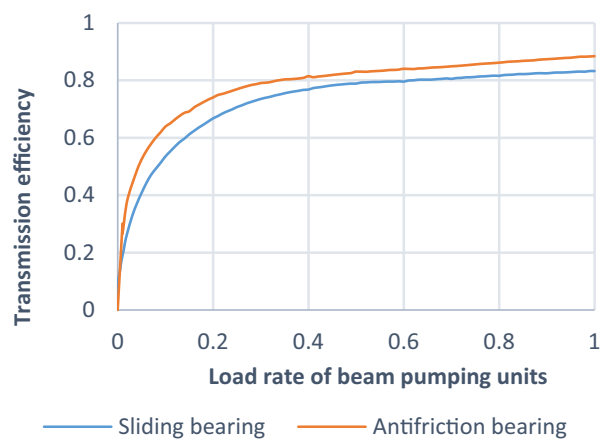

Fig. 1 Transmission efficiency curve of ground equipment (Brown 1980) 
Because the transmission efficiency was nearly a constant value, so it was no need to improve the transmission efficiency. But these equations as shown in Table 3 were very useful to compute the system efficiency of sucker-rod pumping.

\section{Decreasing the polished rod load, $W$}

Polished rod load of the pumping system was induced by the sucker rod that drives the pump to reciprocate. The polished rod load included sucker rod and fluid weight load, inertial load, vibration load, friction load and elastic force etc. Polished rod load reduction was a very effective method to improve the working performance of pumping system. Many researchers devoted to design a shock absorber to reduce the dynamic load of the sucker rod, to design a rod centralizer for reducing the friction load, or to design a load reducer for reducing polished rod load.

\section{Shock absorber}

In general, the metals will turn fatigue under cyclic loading and furthermore will turn fatigue in a shorter time period if the difference between the tension and compression forces is great. Thanks to the cyclic loading for the fatigue failure of the sucker rod string.

Shock absorber device acts as a buffer in the rod string that suppresses the detrimental dynamic effects regularly experienced in a rod pumping system (Tsuru 1987).

In order to increase the fatigue life of sucker rod string, researchers had designed many kinds of shock absorber with an elastic elements such as spiral spring (Komarov and Sun 1981), dish-shaped spring (Komarov 1979; Velichkovich 2005), rubber spring (Zhao et al. 2014) or air spring (Мбагиров and Zhu 1985). The elastic elements serve to both absorb and release energy and to act as a dampening agent which suppresses the oscillating harmonic motion in the sucker rod string.

Especially the air spring shock absorber (Fig. 2), which was developed in Daqing oilfield, achieved the effect of load reduction and energy-saving. The air spring shock absorber's service life is better than other types of shock

Table 3 Correlation function of transmission efficiency

\begin{tabular}{ll}
\hline Content & Correlation function \\
\hline Prime motor & $\eta_{\text {motor }}=-95 \mathrm{e}^{\frac{-P}{2.75}}-0.175 P+95$ \\
Belt & $\eta_{\text {belt }}=0.98-0.98 \mathrm{e}^{\frac{-P}{5.5}}-0.00001 P^{2}$ \\
Gearbox & $\eta_{\text {gearbox }}=0.97-0.97 \mathrm{e}^{\frac{-P}{.9}}-0.00004 P^{2}$ \\
Four-bar linkage & $\eta_{\text {fourbar }}=0.94-0.94 \mathrm{e}^{\frac{-P}{4.8}}-0.00003 P^{2}$ \\
\hline
\end{tabular}

absorber. Figure 3 shows the indicator diagrams with using and without using the air spring shock absorber, the maximum polished rod load decreased by $16.1 \%$, the system efficiency increased by $9.58 \%$ ( $\mathrm{Lu} 2015$ ).

At present, the reason for the less using of shock absorber was that the service life of the elastic elements was too short. The service life of metal spring and rubber spring are both usually not more than 3 months under the cyclic loading of pumping system, but the service life of air spring had more than 6 months. So the shock absorber applied in the oilfield by a limit of short service life of its elastic elements.

The air spring had 6-12 months service lives that were not enough for the pumping system. We expect more than 2 years for service lives of the air spring. There was no a quantitative matching relationship between the structural parameters of the shock absorber and the optimization of oil production. It also limited the application effect and range of shock absorber.

\section{Load reducer}

As shown in Fig. 4, when the load reducer was working, the upper and lower ends of the load reducer piston were located in different pressure systems, casing pipe and oil tube, respectively. In the position of the load reducer device, the pressure of the liquid column in the oil tube is much greater than in the casing pipe, the pressure difference acts on the lower end face of the load reducer piston to produce an upward lift force. In the upstroke, the load reducer aided to drive the sucker rod upward by the pressure difference. In the down stroke, the load reducer was driving downward by the weight of sucker rod. At the last, the load reducer completed a work process and met the purpose of reducing polished rod load.

The load reducer for the sucker rod could decrease the suspension load and increase the pumping system efficiency, and could increase the depth of the pump by the same type beam pumping units. Guo (2014) proposed a design method of the sucker rod string with load reducer in oil pumping system. Zhao et al. (2012) established the simulation model of the longitudinal vibration of the sucker rod string with a load reducer according to the wave equation (Gibbls 1963) and the hydraulic feedback balance model (Guo 2014), and built the difference scheme method to achieve the numerical results.

Therefore, we have achieved the theory and the technology of the application of load reducer. At present, the load reducer was an effective technology to reduce the load of deep well pumping. However, the problems are that when the pumping system pumped the high pour point oil, the sucker rod did not move downward because of the effect of paraffin wax. When the oil fluid contained sand, 


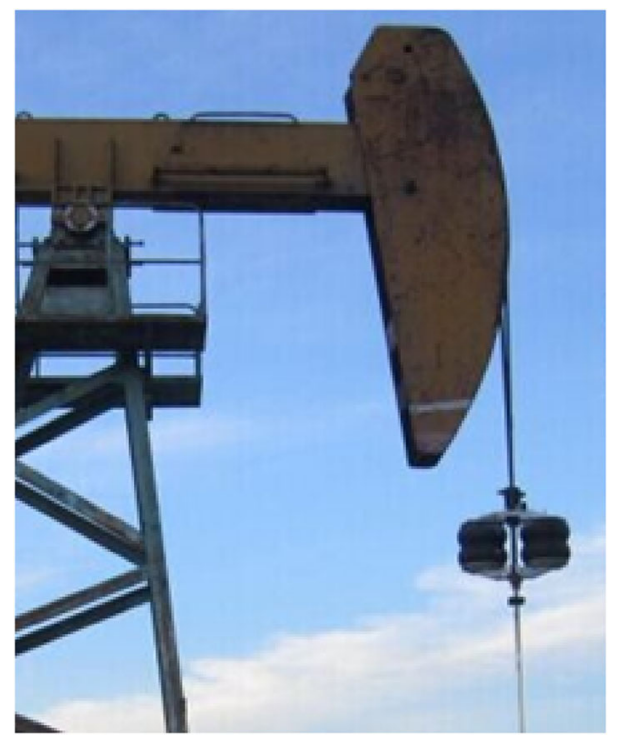

Fig. 2 Shock absorber with pneumatic spring (Lu 2015)

(A)

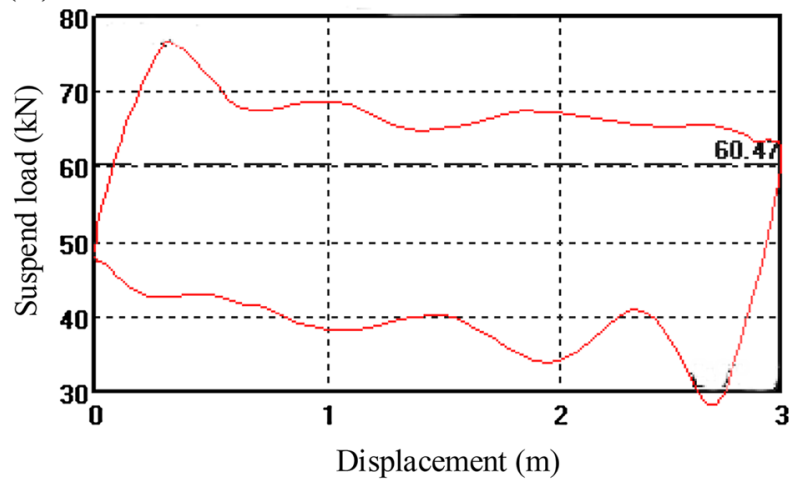

(B)

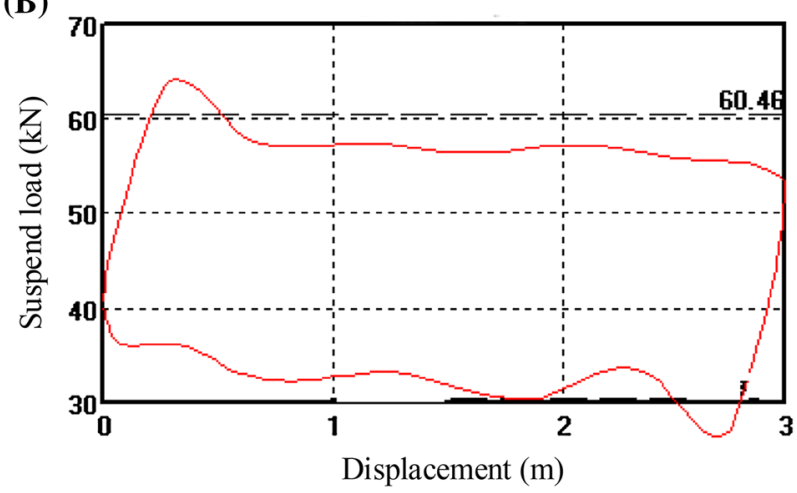

Fig. 3 Dynamometer card with and without shock absorber (Lu 2015). a Before application of shock absorber, $\mathbf{b}$ after application of shock absorber

there would be a little sedimentary sand in the dead water zone locating at the discharge of load reducer. When more sedimentary sand appeared, that would lead to the death of the piston card.

\section{B unbalanced weight of walking beam, $B$}

The conventional pumping units were selected as the basic model to redesign the lower barbell pumping units with keeping the original structure, and a rigid lower barbell device was added at the tail of beam. The "lower" means the center of barbell was not at the same straight line with the beam. The "barbell" refers to the offset balance weight device like a barbell. Due to the reasonable configuration for the position and the quality of lower barbell, the beam balance torque can balance the polished torque better than the conventional pumping units. Therefore, the torque of gearbox decreased and was smooth more than before (Zhu et al. 2009).

The structure of lower barbell pumping units with compound balance had two styles: the interpolating style and upwards style as shown in Fig. 5a, b, respectively. The interpolating style had the characteristic of compact structure, convenient regulation, safety and reliability. The upwards style has the characteristics of being suitable for bigger load, deeper wells, but it has a large structure with relative poor security (Liu 2013).

At the same condition of the structure sizes and the pumping parameters, Figs. 6 and 7 show the two torque curves of conventional pumping units and lower barbell pumping units, respectively. Compared to the conventional pumping units, the lower barbell pumping units has a less fluctuate of the torque curve. Its location of the negative torque is moving from $120^{\circ}$ of upper stroke to the $200^{\circ}$ of down stroke. At the reasonable balance condition, the gearbox peak torque of lower barbell pumping units can

Fig. 4 Load reducer

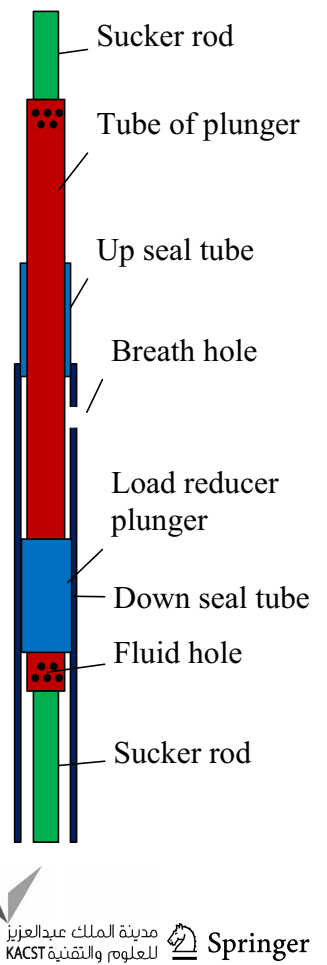


(A)

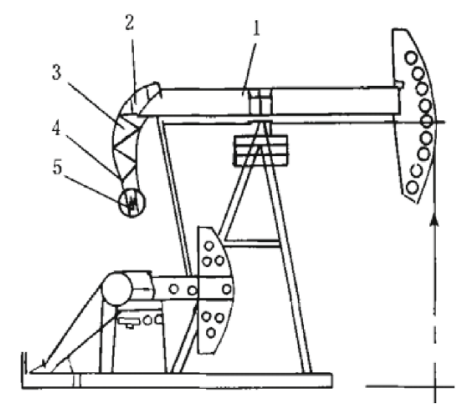

(B)

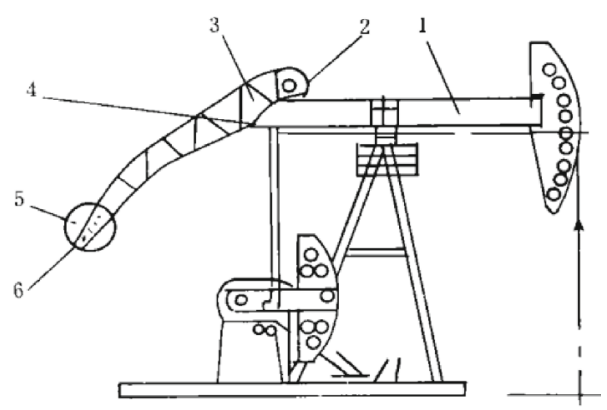

Fig. 5 Compound balanced pumping units with lower balance weight (Liu 2013). a Interpolating style, 1 beam pump units, 2 balance weight of pumping units, 3 lower partial part, 4 lower balance weight, 5 adjust hole. b Upwards style, 1 beam pump units, 2 support, 3 lower partial part, 4 adjust block, 5 lower balance weight, 6 adjust hole

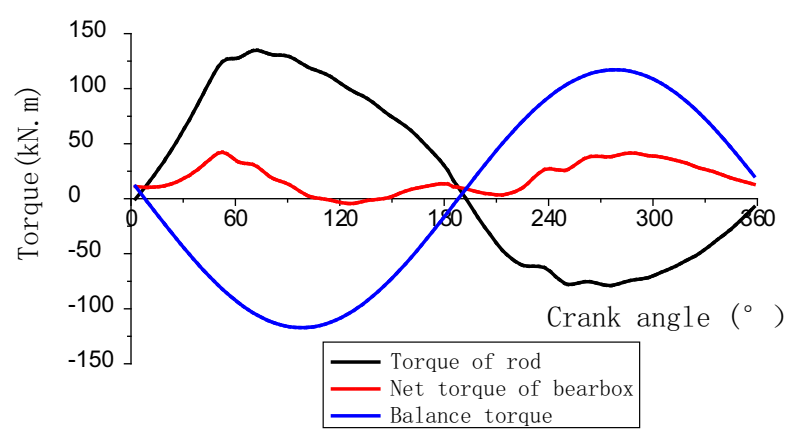

Fig. 6 Torque curve of conventional pumping units (Guo 2015)

decrease by $40 \%$, and its power-saving rate is in the scope of $15-20 \%$ (Guo 2015).

When using the crank balance combined with the lower barbell balance, it is a very complex matter to design a reasonable match method for the optimum balance effect. The theoretical analysis and the application of the fixed lower barbell balance had completed. If the balance torque of the lower barbell can be variable with the polished rod load, the effect of balance will be much better than before, but there are no relevant theoretical reports at present.

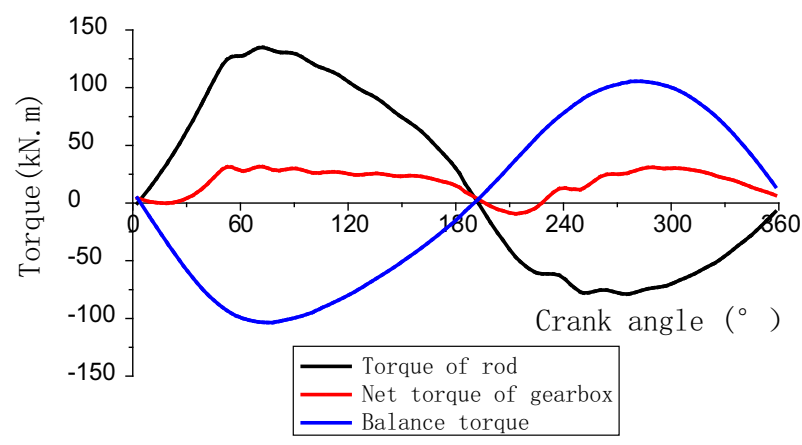

Fig. 7 Torque curve of the lower barbell pumping units (Guo 2015)

\section{Torque factor of the beam pumping unit, $\overline{\mathrm{TF}}$}

The torque factor was defined as follows:

$\overline{\mathrm{TF}}=\frac{A \times R \sin \alpha}{C \sin \beta}$

The torque factor directly is related to the structure sizes of the four-bar linkage. It is a function of the crank angle position. As Eq. (3) shows, if the $\overline{\mathrm{TF}}$ decreases, the net output torque will decrease. If the $\overline{\mathrm{TF}}$ curve shape is alike to the shape of a sine curve, the balance torque will decrease the peak torque and eliminate the negative torque, and achieves a better balance effect than before. To overcome the inherent shortcomings of conventional pumping units, the researchers designed the phased pumping units and the dual-horsehead pumping units with a more reasonable $\overline{\mathrm{TF}}$ curve that can greatly improve the balance effect and the system efficiency.

\section{Phased pump units}

Phased pump units was a beam pumping units with high performance, developing in recent several decades such as CYJY in China and Mark/Mark II in USA. Phased pump units had two differences against to conventional pump units: the first difference was that its gearbox was deviated from the holder, the second difference was that there was a balance phase angle in the center of gravity of counterbalance, the crank always fall behind with phase angle in clockwise. Therefore, in the upstroke, the acceleration and dynamic load of phase pump units decreased, and the peak torque of gearbox decreased (Feng et al. 2016).

At the same working condition and the same structure parameters, the suspend velocity, the torque factor, suspend load and net torque curves of conventional pumping units and phase pumping units are all compared with each other in Fig. 8, respectively.

As seen from Fig. 8a, the max positive velocity of phased pump units' upstroke decreased by $13.8 \%$ than conventional beam pumping units. Figure $8 \mathrm{~b}$ indicates that 
(A)

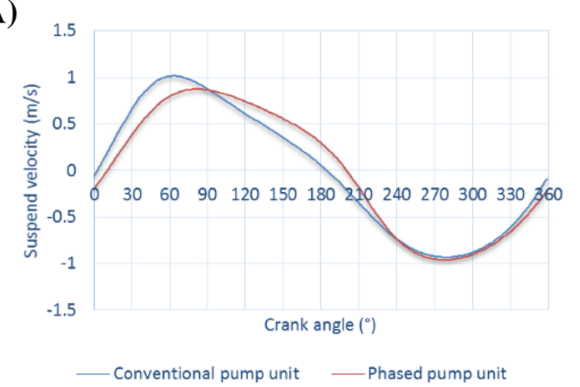

(B)

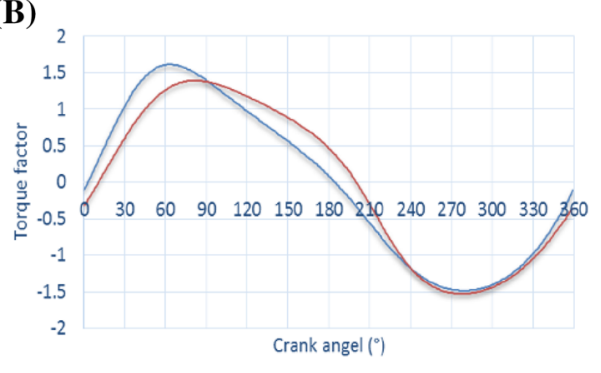

Conventional pump unit _- Phased pump unit

(C)

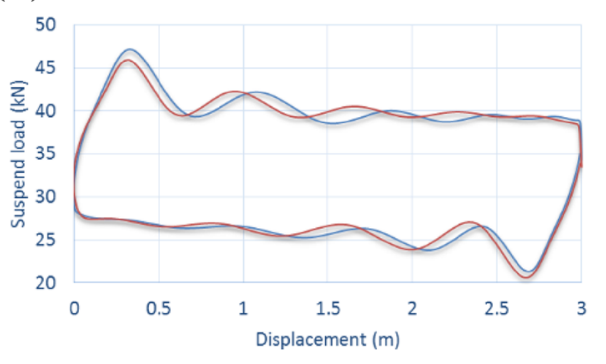

Conventional pump unit _ Phased pump unit

(D)

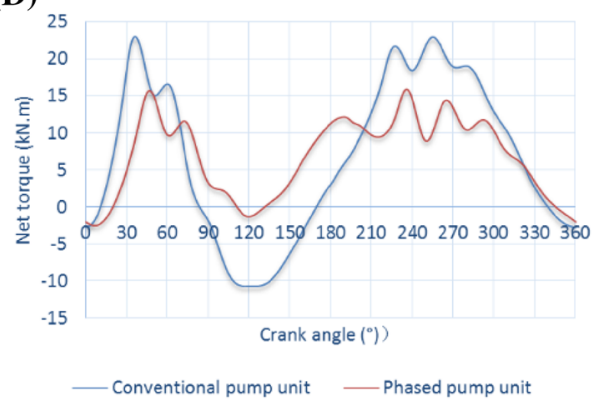

Fig. 8 Characteristic comparison between conventional pump units and phased pump units (Feng et al. 2016). a Suspend velocity, b torque factor, $\mathbf{c}$ polished rod indicator diagram, $\mathbf{d}$ net torque

the maximum value of torque factor of phased pump units decreased by $15.43 \%$ than conventional beam pumping units that could effectively decrease polished rod torque. Figure $8 \mathrm{c}$ shows the maximum load of phased pump units was smaller than conventional beam pumping units about 2.4\%. As Fig. 8d shows that the phased pumping units' peak torque decreased by $34.74 \%$ than the conventional beam pumping units, the valley value of torque decreased by $90.14 \%$. Phased pump units could greatly eliminated the negative torque value. Therefore, the compared results indicate that phased pump units could effectively decrease the polished rod load and could decrease the power consumption.

In general, the working characteristics of phased pump units were slow lifting and fast descending that will be benefit for improving the fullness of pump. In contrast to conventional pump units, its peak values of suspend velocity and acceleration were decreased that will be benefit to decrease the inertial load and the vibration load of polished rod. At the same time, its torque factor curve was more approach sinusoid that indicated the phased pump units would be benefit for balancing polished rod torque (Feng et al. 2016).

\section{Dual-horsehead pump units}

Since the dual-horsehead pumping units were used in 1996, its application results indicated that its energy-saving rate was about 20-30\% (Wang 2006; Chi et al. 2011). The dualhorsehead pump units were reformed with a flexibility reconfiguration, based on the conventional beam pumping units. Its back arm of walking beam was connected a horsehead having a variable radius of curvature. The walking beam connected the linkage rod with flexible drive rope. This variable length four-bar linkage could decrease the torque factor that could decrease the polished torque and avoided the negative torque, and the motor efficiency would be improved (Liu and Feng 2014).

Figure 9a indicates that the peak suspend velocity of dual-horsehead pumping units was decreased by 33\% than conventional beam pumping units at the upstroke. Figure $9 \mathrm{~b}$ shows that the peak and the valley value of torque factor of dual-horsehead pumping units decreased by $29.2 \%$ and by $11.5 \%$, respectively. Figure $9 \mathrm{c}$ shows that the maximum and the minimum polished rod load of dual-horsehead pumping units decreased by $7.01 \%$ and by $4.52 \%$, respectively. Figure $9 \mathrm{~d}$ shows that the peak torque of dual-horsehead pumping units decreased by $40.23 \%$.

The working characteristic of dual-horsehead pump units was slow upstroke and fast down stroke that can increase its system efficiency, and can decrease the maximum suspend velocity and the maximum suspend acceleration that was good for decreasing suspend dynamic load (Liu and Feng 2014). However, the flexible drive rope was easy to worn so that it was not suitable for oil well with higher working load. It is the reason that the dual-horsehead pump units was not more widely used than the phased pump units.

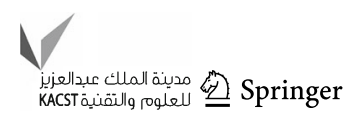




\section{Multi-balance technology}

The conventional beam pumping units has the characteristic of higher energy consumption and low efficiency. The conventional beam pumping units generally were balanced by the crank counterbalance (that also called the primary balance in this paper). Even the balance effect reached the industry standard, the net output torque of gearbox also had the peak torque and negative valley torque. Figure 10 shows that the curve-1 was the torque of rod, the curve- 2 was the balance torque, the curve- 3 was net torque of gearbox and the red region-4 was negative torque. In general, the three-phase asynchronous motor had low slippage about $1-2.5 \%$ so that we treated its velocity as constant.

The torque of rod $T_{\text {rod }}$, shown in Eq. (4), is derived from Eq. (1).

$T_{\text {rod }}=\eta_{\mathrm{b}}^{\mathrm{m}}\left[W-B+\frac{J_{\mathrm{b}} \omega^{2}}{A^{2}} \cdot \frac{\mathrm{d} \overline{\mathrm{TF}}}{\mathrm{d} \theta}\right] \overline{\mathrm{TF}}$

$T_{\text {rod }}$ is a periodic function that meets Dirichlet condition; therefore, the function $T_{\text {rod }}$ can be transformed into Fourier series as following (Feng et al., 2015) in Eq. (5);

$T_{\text {rod }}=c_{0}+\sum_{k=1}^{\infty} c_{k} \sin \left(k \theta+\tau_{k}\right) \quad(k=1,2,3 \ldots)$

where $c_{0}, c_{k}, k$ are all coefficients, $\tau_{k}$ is phase angle.

Figure 11 shows a multi-balance design based on calculated results with Eq. (4). The polished rod torque was an unbalanced gearbox torque. The primary balanced torque was a net output gearbox torque by the crank counterbalance. The secondary balanced torque was a net output net gearbox torque by the primary and secondary counterbalance, and so on.

Daqing General Machinery Plant designed a Secondary Balance Device as shown in Fig. 12 based on the above formulas. The wild field application indicated that, after using the secondary balance device, the active power decreased by $8.57 \%$, the system efficiency increased by $10.02 \%$, the peak torque decreased by $7.88 \%$. Figure 13 shows the prime balanced torque curve and the secondary balanced curve. The secondary balance nearly eliminated all the negative torque that would increase the system efficiency and motor efficiency.

Certainly, the secondary balance device has the function of improving system efficiency, but there are some questions needed to resolve as following:

(a) The phase angle of the secondary balance crank has very important function for the balance effect, but the belt drive always lost rotational speed of crank and the chain drive always broke. How to resolve this question?
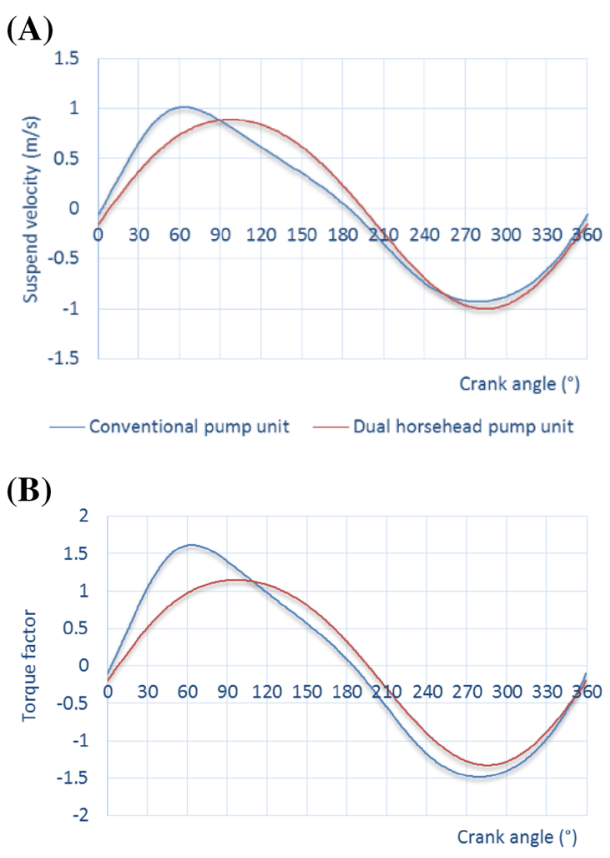

Conventional pump unit _-Dual horsehead pump unit

(C)

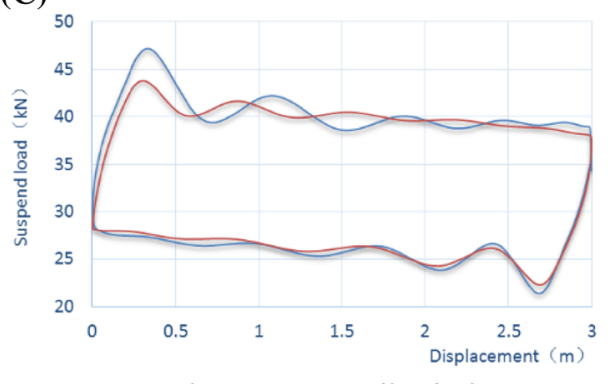

Conventional pump unit _ Dual horsehead pump unit

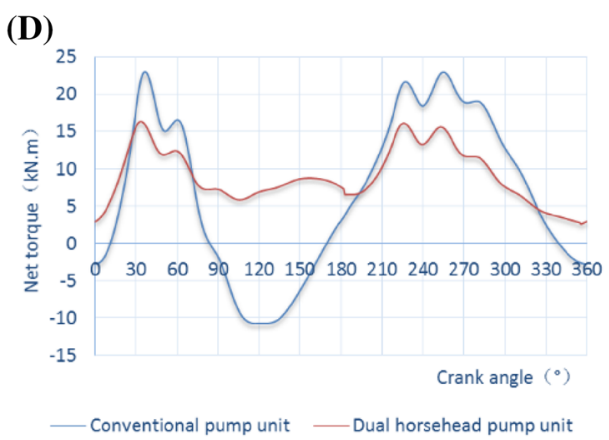

Fig. 9 Characteristic comparison between conventional pump units and dual-horsehead pump units (Liu and Feng 2014). a Suspend velocity, b torque factor, c polished rod indicator diagram, d net torque

(b) The secondary balanced device will increase the overall cost of the units and the operating cost, and will decrease mechanical reliability. How to decrease the high cost? How to improve the mechanical reliability? 


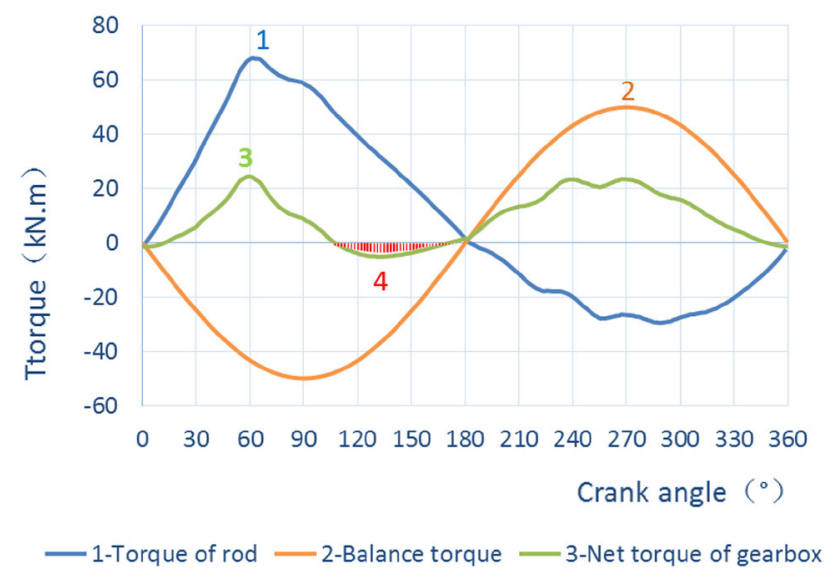

Fig. 10 Crank balance torque for conventional pump units (Feng et al. 2015)

\section{The rotary inertia $J_{\mathrm{b}}$ and $J_{\mathrm{p}}$}

The beam pumping units have many moving parts. In theory, all the moving parts have effects on the output torque of the gearbox, but their effects were not similar to each other. The formula (1) indicates that the equivalent rotary inertias $J_{\mathrm{b}}$ on the beam and $J_{\mathrm{p}}$ on the crank shaft have effects on the net output torque of the gearbox. In the existing literatures (Jiang et al., 2009; Liu, 2003; Zou, 2009), the flywheel-energy-storage device can save energy of pumping units, because its rotary inertia $J_{\mathrm{m}}$, that is transmitted to the gearbox shaft, should be multiplied by the square of the transmission ration. For example, when the transmission ration is 120 , the rotary inertia on the motor shaft will influence the gearbox output torque with 14,400 times. Therefore, adding flywheel device on motor shaft will greatly improve the starting capacity of the motor and will effectively improve the smoothness of the output torque curve of gearbox. Figure 14 represents the flywheel-

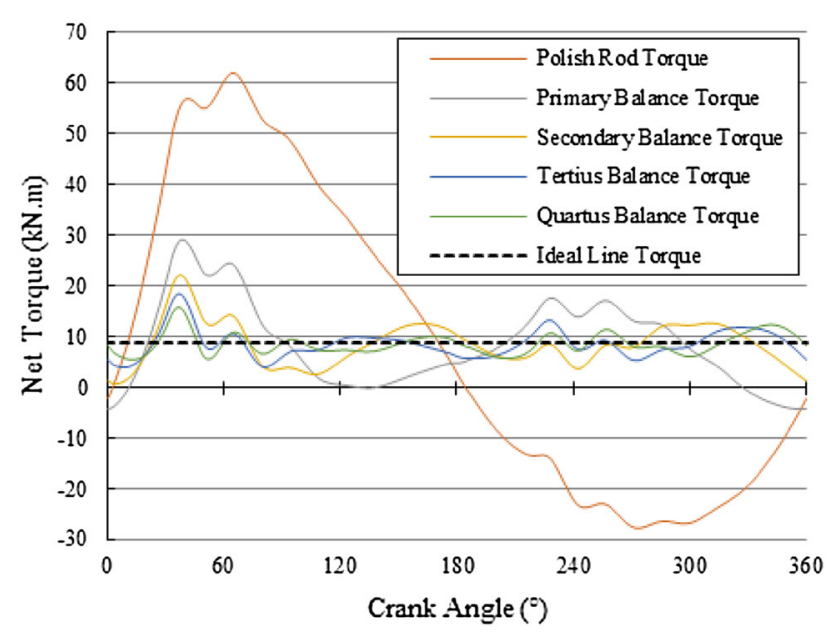

Fig. 11 Multi-balance to polished rod torque (Feng et al. 2015)

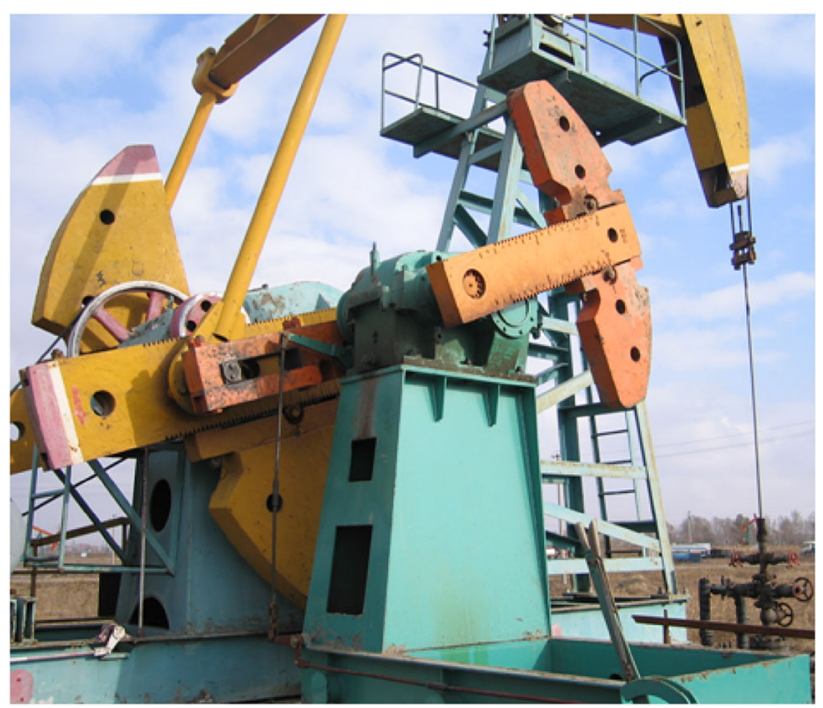

Fig. 12 Secondary balance device (Feng et al. 2015)

energy-storage device in literature (Zhao and Zhao 2009). After application in oilfield, and as shown in Fig. 15, the motor rated-power decreased from 37 to $22 \mathrm{~kW}$, the peak power of the motor decreased by $42 \%$, the negative torque area decreased by $50 \%$ and the comprehensive power saving rate was $20.55 \%$.

Although many documents reported that the flywheelenergy-storage device can improve the motor efficiency and decrease its rated-power, but it is a complex working for studying the rotary inertia's impact on the dynamic load of beam pumping units. At present, there were no systematic researches on this energy-saving technology. For example, the following problems are need to research by researchers of oilfields.

(a) How to match the flywheel mass with the motor slip ratio is reasonable?

(b) Is the flywheel-energy-storage device suitable for permanent magnet synchronous motors?

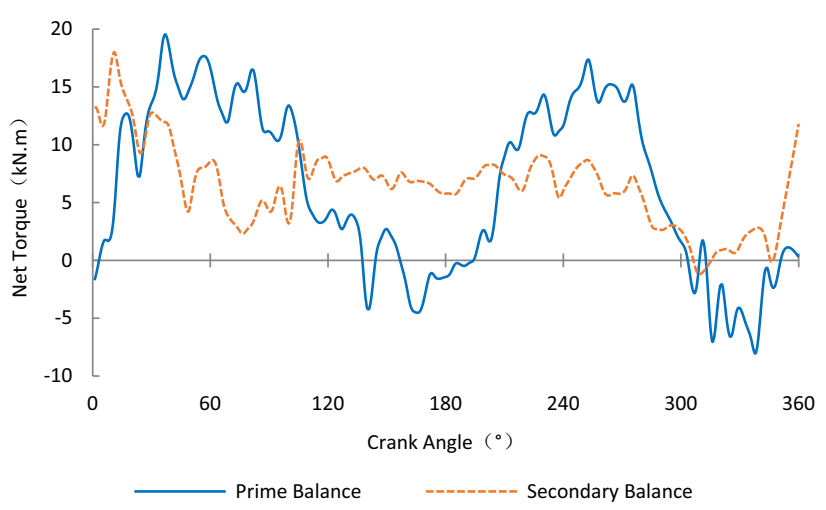

Fig. 13 Net torque curves by prime balance and by secondary balance (Feng et al. 2015) 
(c) How to distribute the rotary inertia of motor in an oil pumping cycle is reasonable and optimal?

(d) Can the dynamic variable speed control technology be application with the flywheel-energy-storage device?

\section{Dynamic variable speed control technology for beam pumping units}

At present, the general idea is that the variable speed drive technology can decrease the polished rod peak load, the energy consumption and increase the oil production of the pumping system. However, in the beginning, the variable speed drive technology only improved the upstroke speed and decreased the down stroke speed of the prime motor. Now the variable speed drive technology can be used to change the speed curve of motor in a pump stroke period to redistribution the speed profile for a more stable operating range and a lower polished rod peak load and a less energy consumption of pumping system.

Gibbs (1984) designed a pump-off controller to sense when pump-off occurred, so that the surface pumping units can be shut down to reduce possible mechanical damage to the equipment and eliminate wasteful use of power. After a preset period of shut off, the pumping units is then restarted.

McKee (1990) rely on the correlation between the amount of filling of the pump and pumping cycle to control the pumping speed for preventing the well from being pumped dry or pump-off. Gibbs (1993) utilized the downhole pump card to detect the various pump problem and control the pumping units such as stop, restart, increasing or decreasing the pumping speed by a controller.

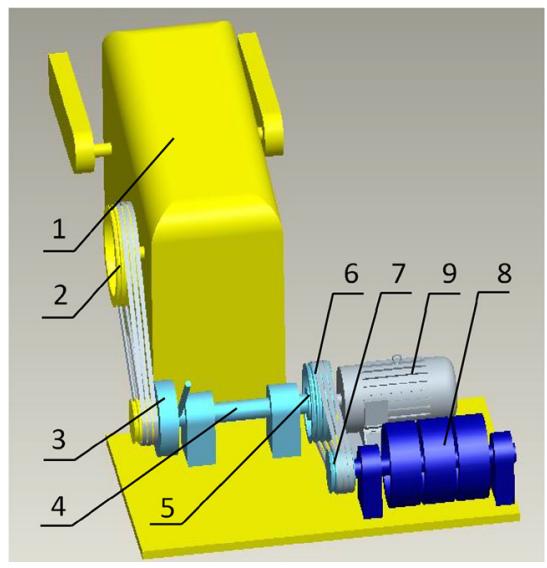

Fig. 14 Schematic diagram of flywheel-energy-storage device (Zhao and Zhao 2009). 1 Gearbox, 2 belt pulley of gearbox, 3 clutch, 4 back shaft, 5 coupling, 6 large belt wheel for growth rate, 7 small belt pulley, 8 flywheel, 9 motor

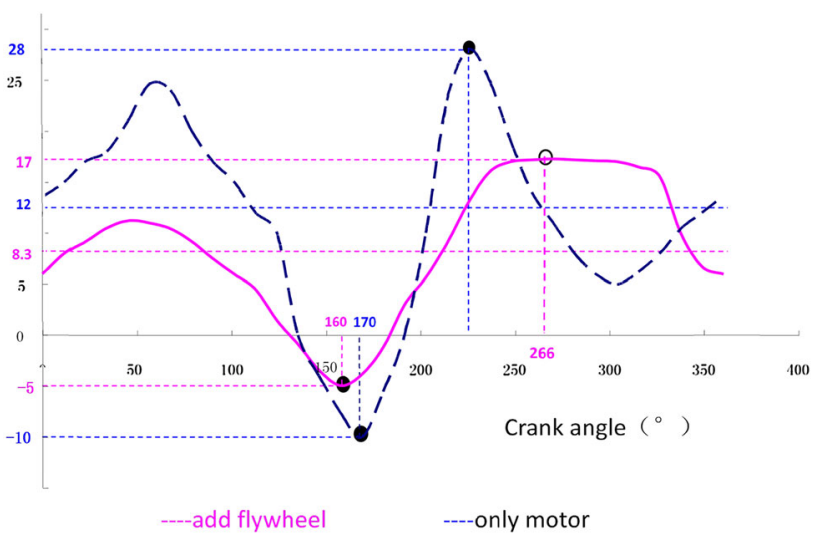

Fig. 15 Comparison of motor power curve with and without flywheel-energy-storage device (Zhao and Zhao 2009)

The long-stroke pumping units often have a mechanical reversing mechanism that may suffer damage if the speed of the reversal at each end of the stroke is too rapid. Therefore, Watson (1993) disclosed a controller that may operate to slow down at both ends of the long stroke, to have different speeds on the upstroke or down stroke in order to increase the production of fluid without increased mechanical wear on the lifting string.

Broren (2005) disclosed a method that at one or more critical position of the rod, the motor speed controller adjusted the speed of the motor to change the movement of the pump rod. However, Broren did not provide the computational methods how to select the position of a polished rod in a stroke cycle. Watson et al. (2005) disclosed three motor speed profiles shown in Fig. 4 for improving the performance of pumping units. The one speed profile in Fig. 16a increased the speed during the upstroke to maximize efficiency and decreased the speed on the down stroke to eliminate pounding against fluid columns. The other two speed profiles in Fig. 16b, c might drive the oil rod strings moving with the trapezoidal velocity profile. After computed, we discovered the first motor speed profile increased the polished rod load that was harmful to pumping system. The other two motor speed profiles could decrease the polished rod peak load, but could not ensure the energysave increasing, and the counter balance degree changed largely.

Palka (2009) disclosed a method that by changing motor speed rapidly with in a single stroke cycle, pump production can be increased while the stresses in the sucker rod and motor energy consumption are reduced (Radzevicius and Clarke, 2012; Palka and Czyz 2015). He described in detail the proposed method for optimization pump performance based on the comprehensive dynamic model of the pumping system and representation of the motor speed in the form of Fourier series defined as functions of polished rod position. The field tests indicated that the efficiency of 


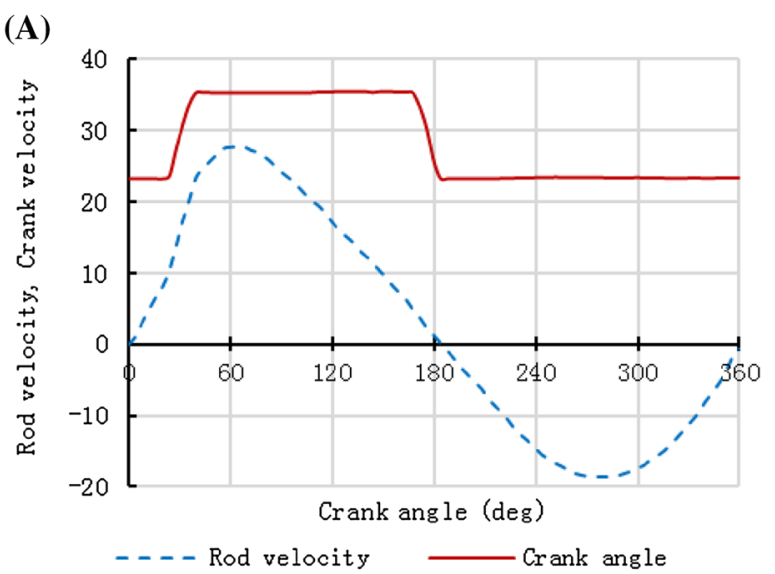

(B)

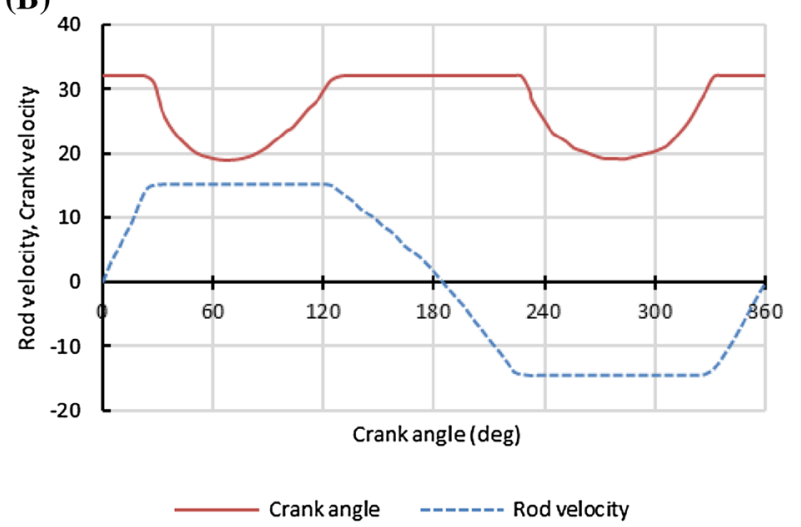

(C)

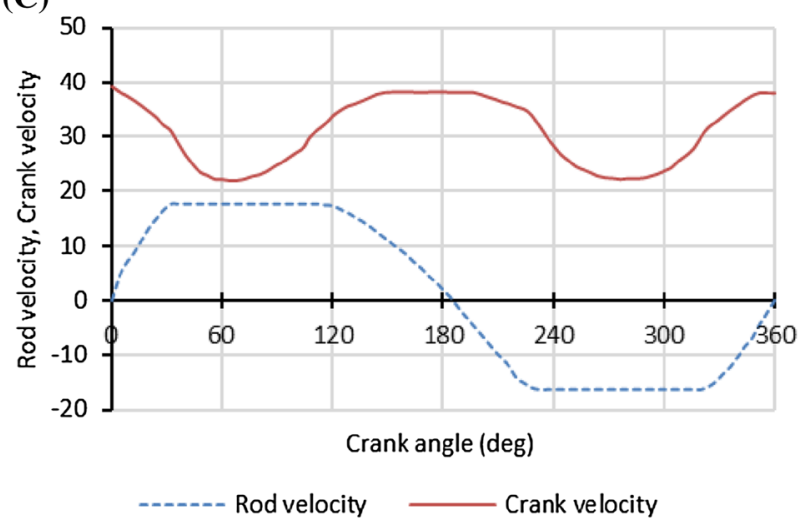

Fig. 16 Variable speed profile for motor (Watson et al. 2005). a Case one, $\mathbf{b}$ case two, $\mathbf{c}$ case three

pumping and the well production all can be improved significantly, respectively. In addition, this variable frequency drive technology can prevent pump overloading, increase time between failures, and provide valuable information for scheduling well maintenance. However, as shown in Fig. 17, the peak torque of down stroke was much bigger than upstroke. The paper's author might not consider that the inertia load of the moving parts of pumping

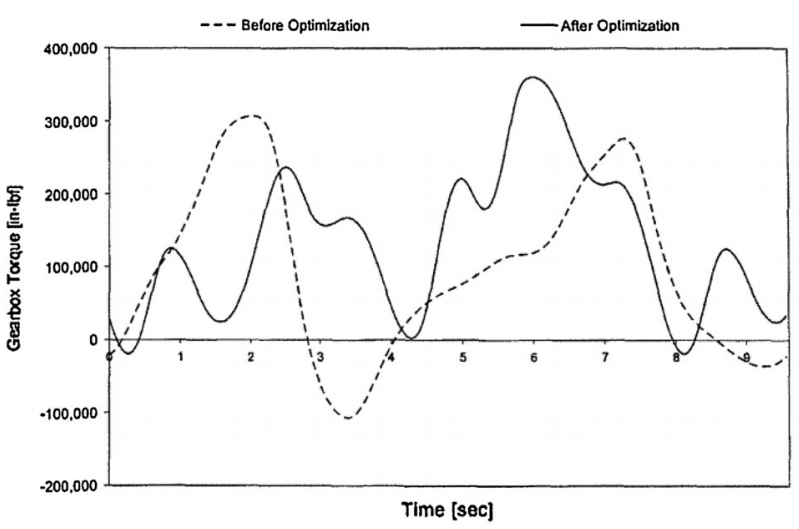

Fig. 17 Gearbox torque after optimization with condition to minimize regenerative torque (Palka 2009)

system would have significant impact on the balance degree.

Because of the inertia load induced by acceleration of the moving parts, the balance degree had changed, and the current balance adjustment method did not meet the need of the variable speed drive operation. With the application of this technology in the oilfield, there would be appearance of the ultra-torque that could damage the gearbox.

In general, the stroke time was only several seconds if the frequency stroke was more than $6 \mathrm{~min}^{-1}$. Therefore, the current technology of the frequency converter could not quickly changed from low (high) frequency to high (low) frequency and would produce much more thermal than before that would burnout the variable frequency drive device.

\section{Development direction and new types of pumping units}

The development direction of the beam pumping units included the following characteristics: the large-scale pumping units for deep well or heavy oil, the low energy consumption, the precise torque balance with higher system efficiency, self-adaption adjustment controlling technology for pumping different oil components, the long stroke without beam, the automation and intelligent controlling devices.

\section{Conclusion}

In order to improve the performance of the beam pumping, many researchers redesigned the beam pumping units' structure or designed the motor drive control technology in order to improve pumping system performance, reduce the gearbox peak torque, reduce the suspend peak load, or 
improve the safety performance. Based on these documents, we can learn as following

(a) The transmission efficiencies of belt, gearbox and four-bar linkage all increased with increasing of load rate.

(b) The air spring shock absorber is an effective buffer to reduce the peak load and the peak torque, and have a longer serve lives. However, the relevant theory of reducing the load mechanism needs to research in detail.

(c) At present, the load reducer was an effective technology to reduce the polished load in deep well pumping. However, the sedimentary sand or paraffin wax in the downhole will lead to the death of the piston card.

(d) Beam balance method is an effective complement method to decrease the gearbox torque.

(e) The torque factor of the four-bar linkage is an important factor to determine the fluctuation of the gearbox torque curve. The phased pump units and the dual-horsehead pump units all have excellent wording performance to be benefit for decreasing the polished rod load and gearbox torque. Based on the Fourier expansion theory of the polished rod torque, the energy-saving mechanism of the multi-crank balance was disclosed perfectly, and the secondary balance technique has verified the validity of this theory. The flywheel-energy-storage device can improve the motor efficiency and decrease the gearbox torque.

(f) At present, the variable speed drive technology is an available method to improve the comprehensive performance of the beam pumping units. Its theory of energy-saving is that the inertia load induced by acceleration of the moving parts is redistribution in the overall time of one stroke that can increase the speed of motor in the low load and decrease the speed of motor in the high load.

Acknowledgements This research was supported by Natural Science Foundation of China (No. 51774091).

Open Access This article is distributed under the terms of the Creative Commons Attribution 4.0 International License (http:// creativecommons.org/licenses/by/4.0/), which permits unrestricted use, distribution, and reproduction in any medium, provided you give appropriate credit to the original author(s) and the source, provide a link to the Creative Commons license, and indicate if changes were made.

\section{References}

Beckwith R (2014) Pumping oil: 155 years of artificial lift. SPE J 66:101-107
Broren SG (2005) Rod saver speed control method and apparatus. Patent US20050095140A1

Brown KE (1980) The technology of artificial methods. Petroleum Publishing Company, Tulsa

Chi P, Yuan WX, Zhao ZP, Liu GB (2011) Energy-saving study and application of dual horsehead pump units. Inn Mong Petol Ind 21:17-18

Feng ZM, Ding HH, Jiang MZ (2015) New secondary balancing method saves energy for crank-balanced rod-pumping application. SPE Prod Oper 30:141-145

Feng ZM, Fang X, Zhao Y, Chen Y (2016) Test study of power saving characteristic of electromotor used in oil well. J Balkan Tribol Assoc 22:1486-1493

Gibbls SG (1963) Predicting the behavior of sucker-rodd pumping systems. J Petrol Technol 15:769-778

Gibbs SG (1984) Method for monitoring an oil well pumping units. Patent US4490094

Gibbs SG (1993) Monitoring and pump-off control with downhole pump cards. Patent US5252031

Guo T (2014) Longitudinal vibration simulation study of sucker rod with load reducer. Inn Mong Petol Ind 24:10-13

Guo X (2015) Energy-saving reconstruction technology of low barbell beam pumping units wells. Priv Sci Technol 21:11-12

Jiang MZ, Yin ZG, Gao CH, Han ZH (2009) Flywheel energy accumulation of beam pumping units and its influence on the power consumption of motor. Oil Gas Field Surf Eng 28:62-63

Komarov ВГ (1979) Shock absorber for sucker rod. Mach Petrol Equip 9:29-31

Komarov ВГ, Sun MM (1981) Shock absorber for sucker rod. Machine and petroleum equipment. China Petrol Mach 13:35-37

Liu YZ (2003) Power-saving analysis for beam pumping units by using flywheel. Oil Gas Field Surf Eng 22:27-28

Liu B (2013) Work performance contrastive analysis of several beam pumping units. J Henan Sci Technol 38:72-73

Liu BW, Feng ZM (2014) Energy-saving mechanism analysis of dual horsehead pump units. Inn Mong Petol Ind 24:43-45

Lu Y (2015) Simulation and test research on air spring beam hanger of beam pumping units. Master thesis, Northeast Petroleum University

Mckee FE (1990) Method and apparatus for controlling a well pumping units. Patent US4973226

Min ZB, Liu Y, Luan QD (2006) Optimum design of conventional pumping units. J Daqing Petrol Inst 30:117-119

МБАГИРОВ М, Zhu ЕМ (1985) A rubber shock absorbers used in defend deep well pump device. World Rubber Ind 26:62-63

Palka K (2009) Optimizing downhole fluid production of sucker rod pump using variable motor speed. SPE J 24:346-352

Palka K, Czyz JA (2015) Method and system for optimizing downhole fluid Production. Patent US9033676

Radzevicius T, Clarke F (2012) Optimization of beam pump well utilizing variable speed drives and remote monitoring software. In: SPE Conference, SPE-148817-MS

Takacs G (2015) Sucker-rod and pumping handbook-production engineering fundamentals and long-stroke rod pumping. Gulf Professional Publishing, Houston, p 4

Tsuru FD (1987) Effects of a cushioning device on dynamic forces exerted on conventional sucker rod pumping systems. In: SPE Production Operations Symposium, Oklahoma City

Velichkovich AS (2005) Shock absorber for oil-well sucker-rod pumping units. Chem Petrol Eng 41:544-546

Wang J (2006) Application and energy-saving study of the 6-typle dual horsehead beam pumping units. Plant Maint Eng 27:16-35

Watson JL (1993) Methods and apparatus for controlling long-stroke pumping units using a variable speed drive. Patent US5246076

Watson J, Aggarwal R, Upadhyay H (2005) Reciprocating pump control system. Patent US6890156B2 
Wu YJ, Liu ZJ, Zhao GX (1994) Sucker rod beam pumping units and technology-pump jack. Petroleum Industry Publishing Company, Beijing

Zhang DS, Feng ZF (2015) Experimental analysis and application of pumping units transmission efficiency. Oil Field Equip 44:48-51

Zhang H, Li CC (2009) Energy-saving technology using on the convention beam pumping units. Mech Eng 2009(37):143-144

Zhao YM, Zhao WH (2009) Design of energy-saving device for beam pumping units. Mech Eng 37:150-151

Zhao HY, Liu ZD, Ding KY, Wang JD (2012) Study on design method of sucker rod with load reducer. Oil Field Mach 28:55-58

Zhao XB, Han QB, Zhang J, Gao DL, Wang YF (2014) Development of the ZJZ type rod string absorber. Hydraul Pneum Seals $34: 45-47$
Zhou GL (2011) Theories and experiment research on pumping units with secondary balancer. Master Thesis in Northeast Petroleum University, pp 1-2

Zhu J, Zhao Y, Chang RQ (2009) A method transforming the conventional beam pumping units into the compound balanced pumping units with downward beam weight. J Daqing Petrol Inst 33:65-67

Zou QJ (2009) Using energy-compensation device to increase the working condition of motor. Oil Gas Field Surf Eng 28:51-52

Zou ZC, Deng LX, Wang HH (2005) Technology of energy saving and latest progress in beam pumping units. J Chengde Petrol Coll $7: 16-19$ 